\title{
Volume cross section of auroral radar backscatter and RMS plasma fluctuations inferred from coherent and incoherent scatter data: a response on backscatter volume parameters
}

\author{
M. V. Uspensky ${ }^{1}$, P. Janhunen ${ }^{1}$, A. V. Koustov ${ }^{2}$, and K. Kauristie ${ }^{1}$ \\ ${ }^{1}$ Finnish Meteorological Institute, Erik Palmenin aukio 1, P.O. Box 503, Helsinki 00101, Finland \\ ${ }^{2}$ ISAS, University of Saskatchewan, 116 Science Place, Saskatoon, Saskatchewan, S7N 5E2, Canada
}

Received: 15 June 2010 - Revised: 25 January 2011 - Accepted: 9 June 2011 - Published: 22 June 2011

\begin{abstract}
Norway and Finland STARE radar measurements in the eastward auroral electrojet are combined with EISCAT CP-1 measurements of the electron density and electric field vector in the common scattering volume to investigate the variation of the auroral radar volume cross section (VCS) with the flow angle of observations (radar look direction with respect to the $\boldsymbol{E} \times \boldsymbol{B}$ electron drift). The data set available consists of $\sim 6000$ points for flow angles of $40-85^{\circ}$ and electron drifts between 500 and $2000 \mathrm{~m} \mathrm{~s}^{-1}$. The EISCAT electron density $N(h)$-profile data are used to estimate the effective electron density, aspect angle and thickness of the backscattering layer. It is shown that the flow angle variation of the VCS is rather weak, only $\sim 5 \mathrm{~dB}$ within the range of the considered flow angles. The VCS values themselves respond almost linearly to the square of both the electron drift velocity magnitude and the effective electron density. By adopting the inferred shape of the VCS variation with the flow angle and the VCS dependence upon wavelength, the relative amplitude of electrostatic electron density fluctuations over all scales is estimated. Inferred values of $2-4$ percent react nearly linearly to the electron drift velocity in the range of $500-1000 \mathrm{~m} \mathrm{~s}^{-1}$ but the rate of increase slows down at electron drifts $>1000 \mathrm{~m} \mathrm{~s}^{-1}$ and density fluctuations of $\sim 5.5$ percent due to, perhaps, progressively growing nonlinear wave losses.
\end{abstract}

Keywords. Ionosphere (Auroral ionosphere; Ionospheric irregularities; Plasma waves and instabilities)

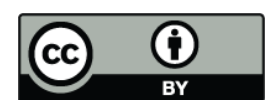

Correspondence to: M. V. Uspensky (mikhail.uspensky@fmi.fi)

\section{Introduction}

The auroral ionosphere is filled with plasma density irregularities whose scales range from tens of kilometers to some centimeters. The irregularities have been observed virtually at all heights (e.g., Fejer and Kelley, 1980) but of special interest have been irregularities of meter scale occurring at the auroral electrojet heights of $90-120 \mathrm{~km}$. This interest has been driven by the fact that (1) the irregularity excitation here is related to the onset of enhanced electric fields of the magnetospheric origin giving an opportunity of studying magnetospheric processes (Greenwald et al., 1978; Nielsen, 1982) and (2) the irregularities themselves modify the background parameters of the ionospheric plasma, for example the electron temperature and conductance (e.g., Schlegel and St.-Maurice, 1981; Buchert et al., 2006).

It is accepted that the auroral electrojet (AEJ) irregularities are excited through the Farley-Buneman (FB) and the gradient-drift (GD) plasma instabilities occurring, first of all, owing to the $\boldsymbol{E} \times \boldsymbol{B}$ drift of the electrons with respect to almost stationary ions (these are strongly controlled by collisions with neutrals). Both instabilities generate plasma waves/density irregularities whose fronts are highly aligned with the geomagnetic field. The irregularities have been extensively studied with obliquely sounding coherent HF, VHF and UHF radars (Fejer and Kelley, 1980; Schlegel, 1996) and in situ rocket measurements (Fejer and Kelley, 1980; Pfaff et al., 1984). While sensors on rockets measure the broadband electron density fluctuation amplitude (EDFA), coherent radars "see" only one Fourier harmonic of plasma density fluctuations as they are only sensitive to the irregularities whose wavelength is half of the radar wavelength, $\lambda_{\text {irr }}=\lambda_{\text {radar }} / 2$. In addition, because of the irregularity

Published by Copernicus Publications on behalf of the European Geosciences Union. 
alignment with the geomagnetic field, in radar experiments, the radiowaves need to meet the plasma wave fronts close to orthogonality, i.e. the auroral backscatter is highly aspect sensitive.

Rocket measurements showed that the EDFA ranges from a few to roughly ten percent, and it varies with height and the $\boldsymbol{E} \times \boldsymbol{B}$ electron drift magnitude (e.g., Fejer and Kelley, 1980). These measurements, however, have been too infrequent to establish the functional relationship between the EDFA and the magnitude and direction of the electron drift $V_{E \times B}$, the major driver of the electrojet instabilities. Establishing such a relationship is important for understanding nonlinear processes of the FB and GD instability development. In this respect, data of coherent scatter radars can be very helpful.

Oksman et al. (1986), following Farley et al. (1981a), proposed a procedure for estimation of the EDFA from the absolute power of auroral coherent echoes. The authors showed that the range of inferred EDFA values is well overlapping with the range of EDFAs reported by in-situ measurements on rockets. Applying the Oksman et al.'s (1986) approach to the Scandinavian Twin Auroral Radar Experiment (STARE) radar measurements in the westward electrojet, Nielsen et al. (1988) confirmed the original findings by Uspensky et al. (1983a, b) and Starkov et al. (1983) that the EDFA increases linearly with $V_{E \times B}$ magnitude but experiences "saturation effect" at drifts above $\sim 600-800 \mathrm{~m} \mathrm{~s}^{-1}$. This is in contrast to Haldoupis et al. (1990) and Timofeev et al. (2002) who did not find signatures of the saturation effect.

The Oksman et al.'s (1986) procedure is based on statistically averaged properties of auroral backscatter. It starts from estimations of the so called volume cross section (VCS) of auroral backscatter, $\sigma_{\mathrm{v}}$, from the absolute power of the echoes which is usually expressed in decibels with respect to the noise level. VCS is the radar cross section per unit volume, i.e. the cross sectional area of an isotropic scatterer which would scatter the same amount of power to the receiver as a unit volume of the scattering medium. To improve accuracy corrections of echo power on aspect angle effect and the volume altitude thickness were introduced. The EDFA derivation procedure relies on $k$ dependence for the VCS; this was inferred from earlier VHF radar measurements at various frequencies (Leadabrand et al., 1967; Chesnut et al., 1968; Moorcroft, 1987). These authors measured the absolute values of the received power and corrected it in accordance with the antenna beamwidth and radar parameters. The irregularity filling of the antenna beams $\left(24^{\circ}, 9^{\circ}, 3^{\circ}\right.$, $1.5^{\circ}, 1^{\circ}$ and $0.4^{\circ}$ at the radar frequencies of $50,139,400$, 850,1210 and $3000 \mathrm{MHz}$, respectively) was assumed to be homogenous as "a reasonable approximation to the actual situation" (Leadabrand et al., 1967; Chesnut et al., 1968). Nobody has made similar measurements since then. Although it is clear that the VCS as a parameter is more difficult to determine than SNR (signal-noise ratio), the absolute VCS is the physical parameter of the scattering medium and it allows one to combine and compare radar data collected by various radars with different parameters and frequencies as well as to derive EDFAs.

According to the theory of coherent scatter (e.g., Farley et al., 1981a), VCS is proportional to the spectral power density of electron density fluctuations, $\left\langle\left(\delta N^{2}(\boldsymbol{k})\right\rangle, k=2 \pi / \lambda_{\text {irr }}\right.$. However, in practice, it is more convenient to handle relative values of the broadband fluctuations because they are less variable and measurable by rocket sensors. Then VCS becomes proportional to square of the broadband electron density fluctuation amplitude (EDFA) $\left\langle(\delta N / N)^{2}\right\rangle$, square of the mean electron density, $N^{2}$, and the spectral power density of the fluctuations with the wave length and direction of $\boldsymbol{k}$ as a part of the full spatial power spectrum of irregularities $f(\boldsymbol{k})$. Oksman et al. (1986) inferred expression for $f(\boldsymbol{k})$ by accepting empirical dependencies for VCS upon the aspect and flow angles and the $k$ dependence. Measuring the mean electron density by an independent instrument, e.g. ionosonde or incoherent scatter radar, the EDFA, in the entire range of fluctuations can be determined. Obviously the Oksman et al. (1986) approach has a number of simplifications but it can be improved/modified once the VCS properties are better understood.

In the present paper we pursue two goals. First, we improve the Oksman et al. (1986) procedure by empirically establishing the VCS flow angle dependence at VHF and correcting the one used in the past. We consider here STARE radar data obtained simultaneously with EISCAT incoherent scatter radar measurements of the $V_{E \times B}$ and electron density profiles. We also introduce and use a better approximation (for the previously published data) for the spatial spectrum of electrojet irregularities $f(\boldsymbol{k})$. Secondly, we apply the improved procedure to STARE/EISCAT radar data collected in the eastward electrojet to investigate the EDFA dependence upon the $V_{E \times B}$ magnitude. The EISCAT $N(h)$-profiles are used to estimate the effective aspect angle of STARE measurements, the effective electron density and the thickness of the irregularity layer.

\section{Modified spatial power spectrum of auroral electrojet irregularities}

Oksman et al. (1986) suggested writing an expression for the volume cross section of auroral backscatter (Farley et al., 1981a; Uspensky et al., 1983a) in the form

$\sigma_{\mathrm{v}}=32 \pi^{4} r_{\mathrm{e}}^{2} N^{2}\left\langle(\delta N / N)^{2}\right\rangle f(\boldsymbol{k})$,

where $r_{\mathrm{e}}$ is the classical electron radius, $N$ is the mean electron density in the backscatter volume, $f(\boldsymbol{k})$ is the 3-D spatial power spectrum of irregularities satisfying the normalization condition of $\int f(\boldsymbol{k}) d^{3}(\boldsymbol{k})=1$. The expression for the spatial power spectrum $f(\boldsymbol{k})$ was derived by considering three known features of the auroral radar backscatter: the aspect angle, the wavelength and the flow angle dependencies. 
These dependences were inferred by statistical averaging of radar data (e.g., Leadabrand et al., 1967; Chesnut et al., 1968; André, 1983). Unfortunately, these are not well established functions, as was implemented by Oksman et al. (1986), for example, they might vary with the height and electric field magnitude. It is open area for studies and for subsequent improvements of our knowledge of the spatial irregularity spectrum.

In this study, similar to Oksman et al. (1986), we use the exponential representation for the aspect angle dependence, $\sigma_{\mathrm{v}} \propto \exp \left(-a_{0}^{2} \tan ^{2} \psi(h)\right)$, where $\psi$ is the aspect angle (which depends on the backscatter altitude) and $a_{0}=50$ (such a value gives the mean power attenuation of $\sim 10 \mathrm{~dB} /{ }^{\circ}$ for the aspect angle interval of $0^{\circ}-3^{\circ}$ ) and the sine-square exponential representation for the flow angle dependence, $\sigma_{\mathrm{v}} \propto \exp \left(-b_{0} \sin ^{2} \theta\right)$, where $\theta$ is the flow angle and $b_{0}$ defines power difference in the directions along the mean electron flow $\theta=0^{\circ}$ and perpendicular to it, $\theta=90^{\circ}$. It is similar in the shape to that assumed by André (1983). For the $k$ dependence, we use a two-mode wave number representation $\sigma_{\mathrm{v}} \propto\left(1+k_{\mathrm{o}}^{2} / k^{2}\right) \exp \left(-k / k_{\mathrm{o}}\right)$, where $k_{\mathrm{o}} \sim 4.7 \mathrm{~m}^{-1}$ is an exponential cutoff of the $k$-spectrum for larger wave numbers, $k>k_{\mathrm{o}}$. It combines 3-D radar part of 1-D power spectrum observed on rockets. The latter is nearly independent of wavelength (Farley, 1985; Pfaff et al., 1984, 1987). From the normalization condition, we obtained a new expression for the spatial power spectrum of the AEJ irregularities in the form

$$
\begin{aligned}
f\left(\boldsymbol{k}_{\mathrm{F}, \mathrm{N}}\right)= & \frac{a_{0} \exp \left(-a_{0}^{2} \tan ^{2} \psi\right)}{\pi^{1 / 2}} \cdot \frac{\left(1+k_{\mathrm{o}}^{2} / k_{\mathrm{F}, \mathrm{N}}^{2}\right)}{3 k_{\mathrm{o}}^{3} \exp \left(\left(k_{\mathrm{F}, \mathrm{N}}-q_{\mathrm{o}}\right) / k_{0}\right)} \\
& \cdot \frac{\exp \left(-b_{0} \sin ^{2} \theta\right)}{2 \pi \exp \left(-b_{0} / 2\right) I_{\mathrm{o}}\left(b_{0} / 2\right)},
\end{aligned}
$$

where $I_{0}\left(b_{0} / 2\right)$ is the modified Bessel function of the 1-st kind. In Eq. (2) we intentionally paired every factor with its own normalization constant. For estimates, we adopt $b_{0}=2.3, q_{\mathrm{o}}=6 \times 10^{-2} \mathrm{~m}^{-1}$ (this is the smallest wave number in the model $k$ spectrum) and the backscatter wave numbers $k_{\mathrm{F}, \mathrm{N}}$ of Finland and Norway STARE radar of 6.02 and $5.86 \mathrm{~m}^{-1}$, respectively. As a further improvement, we use in Eq. (2) the effective aspect angle $\psi$ (Uspensky et al., 2004) as this better reflects changing aspect conditions in the scattering volume. In this study, we also modify the choice of the parameter $b_{0}$ on the basis of the data presented below.

\section{Experimental configuration}

We consider data gathered by the STARE VHF radars (frequencies 143.8 and $140 \mathrm{MHz}$ for the Finland and Norway radars, respectively) between 10:00 and 17:00 UT on 11 and 12 February, 16 and 17 September and 12-15 October 1999. The Kp indices were 4, 3+-4, 4-3+, 4, 5, 3-4, 4-5 and $4-5$, respectively. The Finland radar beam 4 and the Norway radar beam 4 intersect each other at the E-region heights in

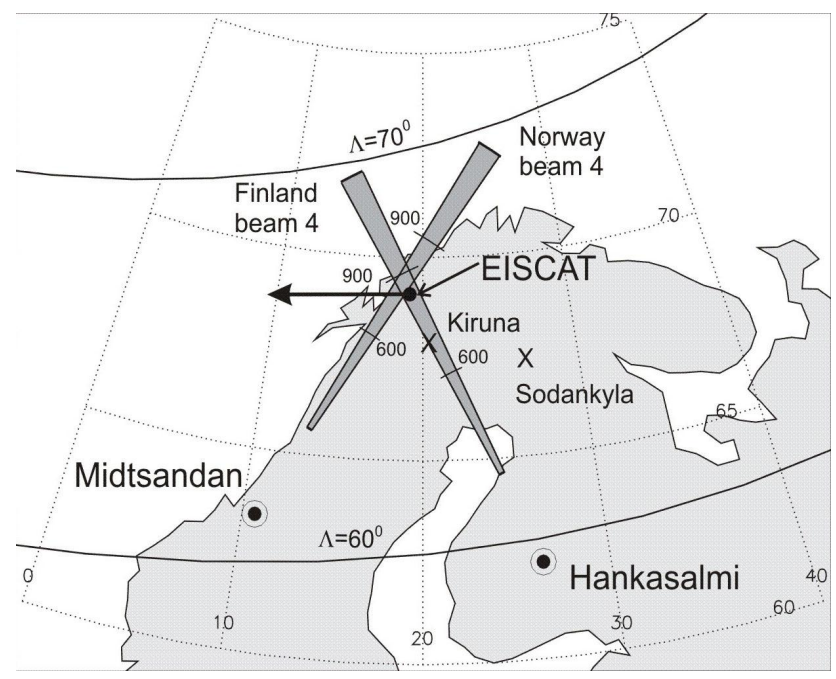

Fig. 1. Orientation of the Hankasalmi (Finland) STARE radar beam 4 and the Midtsandan (Norway) STARE radar beam 4 (assuming 110-km height of backscatter). The short curved lines across the beams are slant range marks of 600 and $900 \mathrm{~km}$. The solid dot denotes an area where ionospheric parameters were measured by the EISCAT incoherent scatter facility, consisting of the UHF transmitter/receiver at Tromso and receivers at Kiruna and Sodankyla (crosses). The solid thick lines indicate PACE (Polar Anglo-American conjugate experiment) magnetic latitudes.

an area (Fig. 1) covering the magnetic flux tubes at which EISCAT measurements of the electric field and electron density were performed, see large dot in Fig. 1. The curved lines crossing the STARE beams (Fig. 1) mark ranges of 600 and $900 \mathrm{~km}$ (assuming the mean backscatter height of $110 \mathrm{~km}$ ).

The EISCAT UHF radar was run in the CP- $1 \mathrm{~K}$ mode with the Troms $\varnothing$ antenna being pointed along the local magnetic field line and the Kiruna and Sodankyla receiver beams being oriented toward a common volume at the height of $\sim 280 \mathrm{~km}$. Such a configuration of the EISCAT beams allowed one to perform tri-static electric field measurements. 1-min averaged data were available. Our afternoon-evening sector data set includes $\sim 6000$ samples for the flow angles of $40-85^{\circ}$ and electron drifts of $500-2000 \mathrm{~ms}^{-1}$. We note that the diameter of the EISCAT beam spot is $\sim 1 \mathrm{~km}$ at the E-region heights and $\sim 2.8 \mathrm{~km}$ at the F-region heights. Thus, the mentioned "large" dot in Fig. 1 is rather small one as compared to the STARE radar cells. The overlap of the two closest STARE radar collecting areas (each of $\sim 12 \times 60-\mathrm{km}^{2}$ size is only $\sim 20 \%$, and the STARE cells are $\sim 700$ times larger than the EISCAT spot at the E-region heights.

\section{Derivation of VCS and backscatter volume parameters}

To determine the backscatter volume cross section we used the so-called basic volume cross section of the STARE radars 

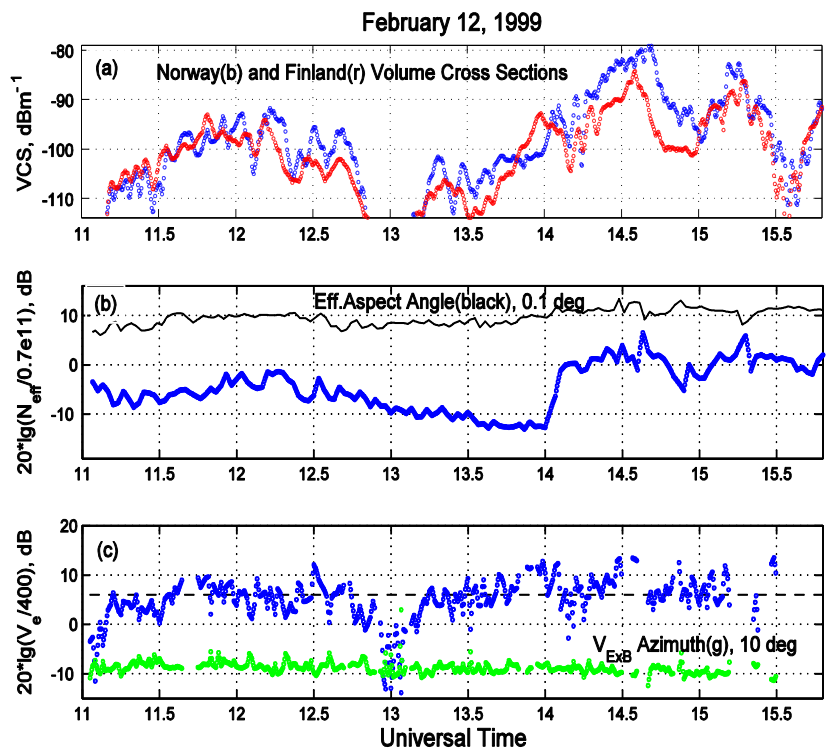

Fig. 2. (a) The volume cross sections, $\sigma_{\mathrm{v}}$, on logarithmic scale corrected on the backscatter volume height thickness and aspect angle, Eq. (3), for the Norway and Finland STARE radars, blue and red line, respectively, for 12 February 1999; (b) The effective electron density in the STARE radar backscatter volumes on logarithmic scale, blue line, and the effective aspect angle on linear scale, black line, both inferred from the EISCAT $N(h)$-profiles, Eqs. (5) and (4); (c) The mean electron drift velocity (on logarithmic scale) and azimuth (on linear scale) in the STARE backscatter volume obtained from the tri-static EISCAT CP1 measurements, blues and green line respectively. Logarithmic scales in panels (a), (b) and (c) were used intentionally to show the expected $\sigma_{\mathrm{v}}$ dependence upon $\left(N_{\mathrm{e}}^{\mathrm{eff}}\right)^{2}$ and $V_{E \times B}^{2}$ (if $\left.\left\langle(\delta N / N)^{2}\right\rangle^{1 / 2} \propto V_{E \times B}\right)$ according to Eq. (1). $\mathrm{LT}=\mathrm{UT}+2 \mathrm{~h}$.

$\sigma_{0}=4.3 \times 10^{-12} \mathrm{~m}^{-1}$ introduced by Oksman et al. (1986) for the slant range of $800 \mathrm{~km}$, the backscatter volume height thickness of $10 \mathrm{~km}$ and SNR of $0 \mathrm{~dB}$ (echo power equals $\mathrm{RX}$ noise power). We decreased this value by a factor of $\sim 1.25$ due to the effective azimuth beam width of the one way the STARE RX antenna (Oksman et al., 1986, used the half-power width). More precisely, for the Norway (Finland) STARE radar at the location of the EISCAT flux tube this parameter is $\sim 3 \times 10^{-12} \mathrm{~m}^{-1}\left(\sim 4.4 \times 10^{-12} \mathrm{~m}^{-1}\right)$, respectively, owing to the difference in the slant range and the backscatter volume azimuthal size. Similarly to the earlier auroral radar measurements (Leadabrand et al., 1967; Chesnut et al., 1968) we assumed that the $4^{\circ}$-azimuth antenna beam filling by ionospheric irregularities is reasonably homogenous. The general radar parameter uncertainty we estimate as $\pm 2 \mathrm{~dB}$ which gives a factor $\sim 1.26$ uncertainty in the EDFA magnitude. The measured volume cross section was calculated from
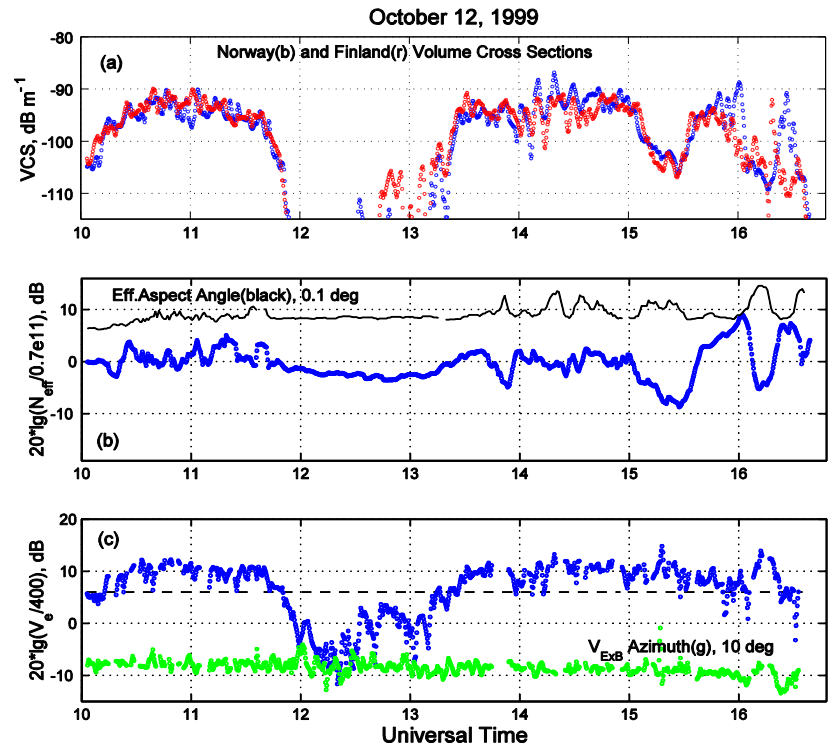

Fig. 3. The same as in Fig. 2 but for 12 October 1999.

$$
\begin{aligned}
\sigma_{\mathrm{v}}(N, F)= & \operatorname{SNR} \cdot \sigma_{0}(N, F) \times\left(10^{4} / \Delta H_{\mathrm{eff}}\right) \\
& \cdot \exp \left[a_{0}^{2}\left(\tan ^{2} \psi_{\text {eff }}-\tan ^{2} \psi_{0}\right)\right],
\end{aligned}
$$

where SNR is the signal-to-noise ratio presented on the linear scale, $\Delta H_{\text {eff }}$ is the volume thickness (in height) in meters (computed as explained later), and $\psi_{\text {eff }}, \psi_{0}$ are the effective and geometric aspect angles. The aspect angle term in Eq. (3) brings all VCSs to the geometrical aspect angle of $\sim 0.9^{\circ}$ at altitude $110 \mathrm{~km}$. If to think about the orthogonal backscatter VCS, then from Eq. (2), it is in $\sim 2$ times stronger.

To estimate $N_{\mathrm{e}}^{\text {eff }}, \psi_{\text {eff }}$ and the volume height thickness $\Delta H_{\text {eff }}$ we used the EISCAT $N(h)$-profiles and inferred from them the backscatter power height profiles $P(h)$, as described by Uspensky et al. (2004). The relative backscatter power at a specific height was expressed as $P(h) \propto\left\langle(\delta N / N)^{2}\right\rangle\left(N(h) / N_{\max }\right)^{2} \exp \left(-a^{2} \tan ^{2} \psi(h)\right)$, where $\left\langle(\delta N / N)^{2}\right\rangle^{1 / 2}$ was assumed to be height-independent (for simplicity) in agreement with some rocket measurements, e.g. by Pfaff et al. (1984). For the sake of simplicity we accepted the linear rate of the aspect angle change with height of $0.075^{\circ} \mathrm{km}^{-1}$, although the real Finland and Norway radar height gradients in EISCAT flux tube are $\sim 0.07$ and $0.08^{\circ} \mathrm{km}^{-1}$, respectively. The height of zero aspect angle was assumed to be $100 \mathrm{~km}$ for both radars, although they are closer to $\sim 97$ and $\sim 99 \mathrm{~km}$ for the Finland and Norway radars, respectively (Koustov et al., 2002). These simplifications are reasonable since inside the radar collecting area of $\sim 12 \times 60 \mathrm{~km}^{2}$, the echo height might vary by several $\mathrm{km}$ up or down. The effective parameters were computed as

$\psi_{\mathrm{eff}}=\int P(h) \psi(h) d h / \int P(h) d h$, 
$N_{\mathrm{e}}^{\mathrm{eff}}=\left(\int P(h) N^{2}(h) d h / \int P(h) d h\right)^{1 / 2}$,

$\Delta H_{\mathrm{eff}}=\int P(h) d h / P_{\max }(h)$.

For our afternoon-evening events the effective parameters are primarily sensitive to the lower part of EISCAT $N(h)$ profiles due to gradual power attenuation with height (controlled by the aspect angle effect).

Figures 2 and 3 give two typical examples of temporal behaviour of the Finland and Norway VCS, $\sigma_{\mathrm{v}}$, along with the EISCAT-measured mean electron drift velocity, $\boldsymbol{V}_{E \times B}$, and the effective electron density $N_{\mathrm{e}}^{\mathrm{eff}}$. Such presentation allows one to quickly assess the role of various factors determining VCS.

To facilitate the assessment, all three panels in Figs. 2 and 3 use similar logarithmic scales fory axes (by taking for example $10 \cdot \log _{10}\left(\sigma_{\mathrm{v}}\right)$ for VCS $)$. In the middle panel, the $y$ scale reflects the logarithm of the normalized value of $\left(N_{\mathrm{e}}^{\mathrm{eff}}\right)^{2}$, blue circles. In the bottom panel, the $y$ scale reflects the logarithm of the normalized value of $V_{E \times B}^{2}$, blue circles. The normalizing values of $0.7 \times 10^{11} \mathrm{~m}^{-3}$ and $400 \mathrm{~m} \mathrm{~s}^{-1}$ are the typical electron density and the FB instability threshold in the high-latitude ionosphere.

For a logarithmic scale, let us recall that a factor of 2 change of $N_{\mathrm{e}}^{\text {eff }}$ or $V_{E \times B}$ corresponds to a $6-\mathrm{dB}$ change of the mentioned values in the middle and bottom panel. The dashed line at bottom panels is a $6-\mathrm{dB}\left(800 \mathrm{~m} \mathrm{~s}^{-1}\right)$ reference level for $V_{E \times B}$ velocity. In Figs. 2 and 3 we also present, using linear scale, the effective aspect angle $\psi_{\text {eff }}$, in units of $0.1^{\circ}$ (thin black line at the middle panels) and the azimuth of the electron drift velocity vector $\boldsymbol{V}_{E \times B}$ in units of $10^{\circ}$ (green line at the bottom panels). Note that the smallest (largest) effective aspect angle was $\sim 0.9^{\circ}\left(1.5^{\circ}\right)$ and the electron drift velocity azimuth was gradually changing in time (in both cases) from $\sim-85^{\circ}$ to $\sim-100^{\circ}$.

The Finland VCSs in Figs. 2 and 3 were corrected on $R^{-3}$ range dependence taking into account the Finland-Norway radar range difference. It adds $2.4 \mathrm{~dB}$ to the Finland VCSs. According to Figs. 2 and 3, the VCS values for the Norway and Finland radar follow each other reasonably well in spite of the fact that the overlap of radar cells is only $\sim 20 \%$. One can conclude that the afternoon-evening AEJ geophysical conditions in the Norway and Finland signal collecting areas were similar.

The data in Figs. 2 and 3 show the VCS response (1) to the electron drift velocity alone (similar to Haldoupis et al., 1990), (2) to the electron density alone (similar to Starkov et al., 1983) and (3) to both the velocity and density (similar to Nielsen et al., 1988, and Haldoupis et al., 1990). A common feature of the events is the appearance (disappearance) of echoes over (under) -(115-110)- $\mathrm{dB} \mathrm{m}^{-1} \mathrm{VCS}$ level for which the electron drift velocity is close to $+3 \mathrm{~dB}$ $\left(\sim 560 \mathrm{~m} \mathrm{~s}^{-1}\right)$, see the bottom panels. Such case can be seen in Fig. 3 between 10:00 and 12:00 UT where both the Norway and Finland $\sigma_{\mathrm{v}}^{\mathrm{N}}$ and $\sigma_{\mathrm{v}}^{\mathrm{F}}$ react on $V_{E \times B}$ velocity increase and decrease. For these periods, the $V_{E \times B}$ controls the echo appearance (disappearance), irrespective on the value for the $N_{\mathrm{e}}^{\mathrm{eff}}$.

The case (2) with the power control by the electron density can be seen in Fig. 2 between 14:00-15:30 UT and in Fig. 3 after 15:00 UT. For example, at $\sim 16: 20 \mathrm{UT}$ in Fig. 3, both $\sigma_{\mathrm{v}}^{\mathrm{N}}$ and $\sigma_{\mathrm{v}}^{\mathrm{F}}$, fall by $16-18 \mathrm{~dB}$ down. These were accompanied by quick $14-15 \mathrm{~dB}$ decreases of $N_{\mathrm{e}}^{\mathrm{eff}}$ values to $\sim-4 \mathrm{~dB}$ level $\left(\sim 0.4 \times 10^{11} \mathrm{~m}^{-3}\right)$. This happened even though $V_{E \times B}$ magnitudes reached their extreme values of $1600-1700 \mathrm{~m} \mathrm{~s}^{-1}$ ( $\sim 3 \mathrm{~dB}$ over previous values at 14:30-15:30 UT). When the electron drift velocities were larger than $\sim 800 \mathrm{~ms}^{-1}$, there were cases (3) with both $V_{E \times B}$ and $N_{\mathrm{e}}^{\text {eff }}$ variations responsible for $\sigma_{\mathrm{v}}$ magnitude, e.g. between 13:00 and 15:30 UT in Fig. 2a.

\section{VCS dependence on the flow angle, plasma drift and electron density}

All STARE/EISCAT data available were grouped in four velocity bins centered at 500, 700, 1000 and $1400 \mathrm{~m} \mathrm{~s}^{-1}$ (these values are different by a factor of $\sim 2^{1 / 2}$ ) and VCS were plotted in various bins of the flow angle, Fig. 4a, b. The VCS flow angle dependence for the whole data set is shown by dotted line. The curves in Figs. 4a, b indicate that the flow angle variation is weak and, for some parts, irregular.

If we suggest that the volume cross section is controlled only by the electron drift velocity, i.e. $\sigma_{\mathrm{v}} \propto V_{E \times B}^{2}$, then the velocity increment (decrement) by a factor of $2^{1 / 2}$ should increase (decrease) VCS by $3 \mathrm{~dB}$. An increase of mean VCS values averaged over all flow angles for velocities of 500, 700, 1000 and $1400 \mathrm{~ms}^{-1}$ is $\sim 5.9, \sim 5.3$ and $\sim 3.2 \mathrm{~dB}$ and $\sim 4.2, \sim 4.0, \sim 2.2 \mathrm{~dB}$ for the Norway and Finland STARE radars, respectively. Thus, for moderate electron drifts the VCS increments are nearly 1.5-2 times larger than one would expect from the assumption. For high electron drifts, $V_{E \times B}>1000 \mathrm{~ms}^{-1}$, VCS increments are close to or even smaller than $3 \mathrm{~dB}$.

Figure 5a, b shows the VCS dependence upon the effective electron density in the backscatter volume. Here the $\mathrm{x}$-axis argument is slightly more complicated

$x \propto\left(N_{\mathrm{e}}^{\mathrm{eff}} / 0.7 \times 10^{11}\right)^{2} \times\left(10^{4} / H\right) \cdot \exp \left(a_{0}^{2}\left(\tan ^{2} \psi-\tan ^{2} \psi_{0}\right)\right.$,

where, besides $N_{\mathrm{e}}^{\mathrm{eff}}$, there is (similar to Eq. 3) a correction on the volume height thickness and the aspect angle.

VCSs measured for all flow angles were grouped in the same four velocity bins with a factor of $\sim 2^{1 / 2}$ increments in the velocity magnitude $\left(500,700,1000\right.$ and $1400 \mathrm{~ms}^{-1}$ ) and averaged over five equal bins of the argument $x$ given in Eq. (5), blue, green, yellow and red lines, respectively. Blue 

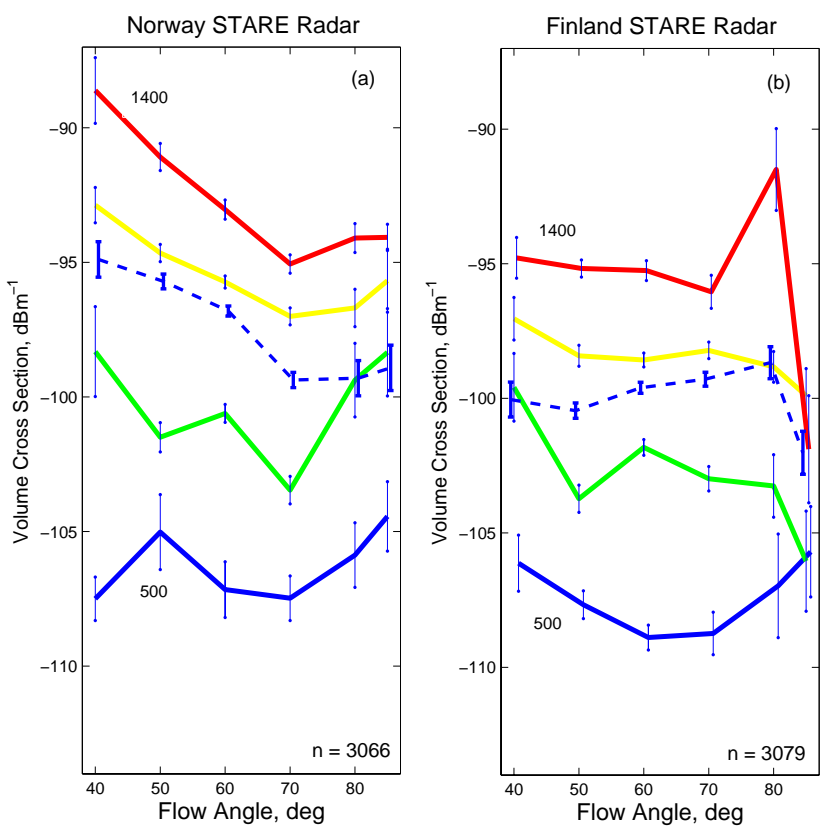

Fig. 4. (a) The Norway and (b) Finland radar VCS dependence upon the flow angle for various mean electron drift velocities. The measured VCSs were grouped into six $10^{\circ}$-bins of the flow angle centred at $40^{\circ}, 50^{\circ}, 60^{\circ}, 70^{\circ}, 80^{\circ}$ and $85^{\circ}$ and averaged over four intervals of the electron drift velocity centred at 500, 700, 1000 and $1400 \mathrm{~m} \mathrm{~s}^{-1}$, blue, green, yellow and red lines, respectively. Dashed line shows the flow angle dependence without binning according the electron drift velocity. Vertical bars are error estimates for the average values.

dots above and below the curves show error bars of the mean VCS values.

The VCS dependence upon plasma density in the backscatter volume can be well seen by green, yellow and red lines running roughly parallel to the bisectors, dashed line, as expected from Eq. (1). Such dependence becomes weaker and less regular for the electron velocity close to the FB instability threshold $\left(\sim 400 \mathrm{~m} \mathrm{~s}^{-1}\right)$.

Figure 5a, b shows that both larger electron drift velocity and larger plasma density correspond to larger volume cross sections. The VCS increase with $V_{E \times B}$ under moderate and large electron densities is reasonably regular one. When $V_{E \times B}$ is close or more than $1000 \mathrm{~m} \mathrm{~s}^{-1}$, a saturation of the VCS growth rate can be seen. Similar saturation was discussed in the previous subsection, Figs. $4 \mathrm{a}, \mathrm{b}$. In the area of smallest electron densities, $N_{\mathrm{e}}^{\text {eff }}<\sim 0.4 \times 10^{11} \mathrm{~m}^{-3}$, the VCS response on $V_{E \times B}$ is less regular.

\section{Amplitudes of electrostatic fluctuations from STARE/EISCAT measurements}

By considering the measured STARE VCSs, the backscatter volume parameters inferred from the EISCAT data and the
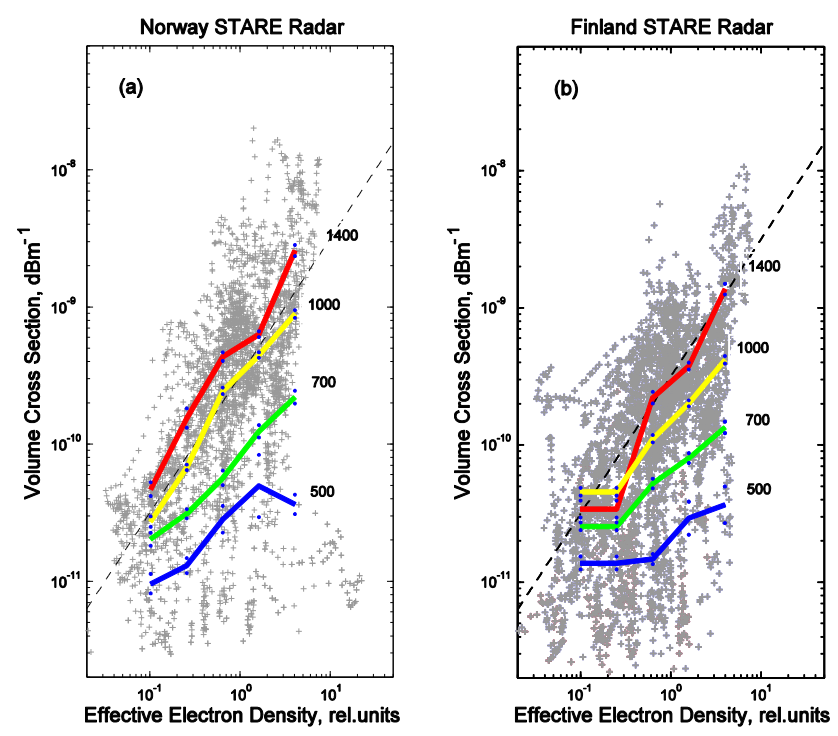

Fig. 5. (a) The Norway and (b) Finland radar VCSs dependence upon the effective electron density for various mean electron drift velocities. The measured VCSs were grouped in five equal electron density bins and averaged over four intervals of the electron drift velocity centred at 500, 700, 1000 and $1400 \mathrm{~m} \mathrm{~s}^{-1}$, blue, green, yellow and red lines, respectively. Blue dots show the span of the error bars around each mean VCS magnitude.

spatial power spectrum of auroral irregularities (Eq. 2) with $b_{0}=2.3$, we inferred $\left\langle(\delta N / N)^{2}\right\rangle^{1 / 2}$ by "inverting" Eq. (1), similar to Oksman et al. (1986), Fig. 6a, b. Here blue, grey and pink dots correspond to weak $\left(\leq 0.4 \times 10^{11} \mathrm{~m}^{-3}\right.$ ), moderate and high $\left(\geq 1.0 \times 10^{11} \mathrm{~m}^{-3}\right)$ effective electron density. In spite of significant data spread, the averaged EDFA magnitudes (for four electron drift velocity bins of $500,700,1000$ and $1400 \mathrm{~m} \mathrm{~s}^{-1}$ ) represented by dark grey colour are $2-5 \%$ and thus reasonably consistent with in situ rocket measurements in the auroral E-region (e.g., Ogawa et al., 1976, 1981; Pfaff et al., 1984; Schlegel, 1992). The sparsely populated clouds of points in the upper and lower parts of the panels are probably due (at least partly) to the difference in the large/small collecting areas of the STARE and EISCAT radars and occasional local spikes (drops), e.g. in the EISCAT electron density.

Despite the spread of points, one can reveal a tendency of blue (red) points in the centre of clouds to be above (below) the mean grey curve. It means that the EDFA magnitudes seem to be slightly larger (smaller) for condition with small, (large) plasma density. Many of lowest EDFAs (seen better in the Norway STARE data) appear for condition of large plasma density.

One can conclude from Fig. 6a, b that the mean EDFA magnitude exhibits a nearly linear increase with the electron drift velocity (ionospheric electric field) and a progressively increasing saturation for the electron drift velocities above $\sim 1000 \mathrm{~m} \mathrm{~s}^{-1}$. Despite the data spread, the error bars of the 


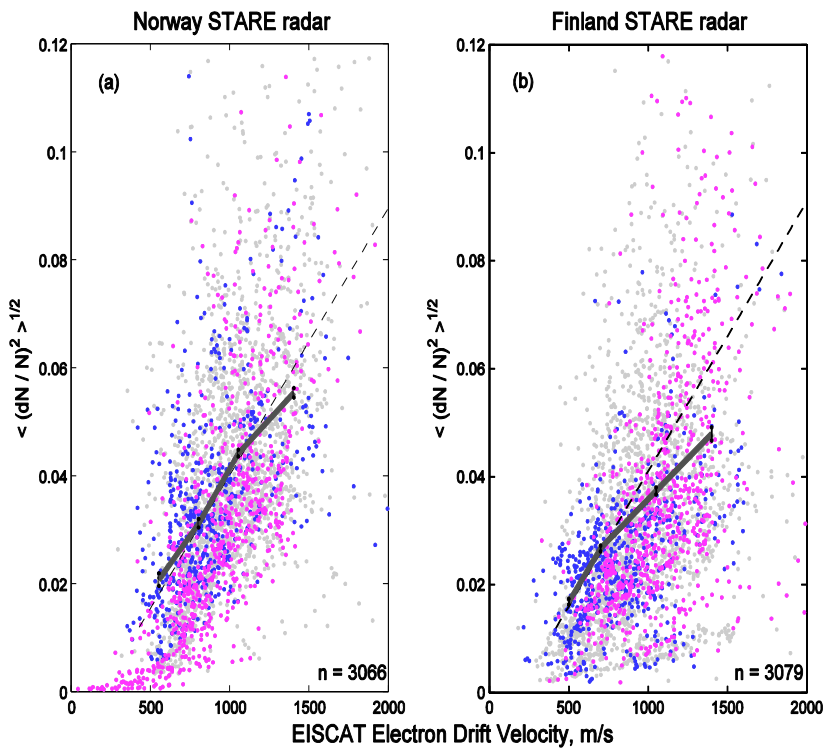

Fig. 6. Dependence of the RMS fractional electron density fluctuation amplitude (EDFA), $\left\langle(\delta N / N)^{2}\right\rangle^{1 / 2}$, (inferred from (a) Norway and (b) Finland data) upon the mean electron drift velocity, $V_{E \times B}$. All measured EDFAs (blue, grey and pink dots) were grouped and averaged over four bins of the electron drift velocity centred at 500 , 700,1000 and $1400 \mathrm{~m} \mathrm{~s}^{-1}$. Dashed lines are eye-adjusted lines colocating with the low-velocity parts of the EDFA curves. Blue, pink and grey dots correspond to the low/high/middle effective electron density of $\leq 0.4 \times 10^{11} \mathrm{~m}^{-3}, \geq 1.0 \times 10^{11} \mathrm{~m}^{-3}$ and within the interval of $(0.4-1.0) \times 10^{11} \mathrm{~m}^{-3}$, respectively.

mean EDFA magnitudes are small (even smaller than the curve line width). We note that the bisectors, dashed lines in Fig. 8a, b, were arbitrary shifted to the right along x-axes (implying $\left\langle(\delta N / N)^{2}\right\rangle^{1 / 2} \propto\left(V_{E \times B}+d\right)$ to better fit to the near linear startup part of the EDFA curves.

\section{Discussion}

\subsection{VCS dependence upon the flow angle}

Figure $4 \mathrm{a}, \mathrm{b}$ revealed two types of tendencies. The first type occurs for echoes with the strongest VCSs, $\geq 10^{-9} \mathrm{~m}^{-1}$ $\left(10^{-8}-10^{-9} \mathrm{~m}^{-1}\right.$ for non-averaged data). For these echoes there is a clear trend of the VCS increase at smallest flow angles. Similar values of the strongest STARE VCS were found earlier by Moorcroft (1987). The second type includes echoes with moderate VCSs, roughly between $\sim 2 \times 10^{-10}$ and $\sim 2 \times 10^{-11} \mathrm{~m}^{-1}$. These echoes show less regular the flow angle variation.

In the past, the flow angle dependence of auroral backscatter power was a subject of focused studies by André (1983), Mattin and Jones (1987), and Timofeev et al. (2002) in the VHF band and by Moorcroft $(1996 a, b)$ in the UHF band. Their results are partially summarized in a review by Schlegel (1996). André (1983) found that at large drift velocities the STARE SNRs are smallest at $\theta \approx 90^{\circ}$ and they are $\sim 20 \mathrm{~dB}$ larger at $\theta \approx 0^{\circ}$. However, André's statistics was a combination of evening and morning data with unknown geophysical conditions. Also, to cover gaps in statistics he mirrored the STARE data with the flow angles $\theta^{*}>\pi$ to values of $\left(\theta=\left|\theta^{*}-2 \pi\right|\right)$ and merged them in one data set.

Mattin and Jones (1987) studied the flow angle dependence for power using SABRE VHF measurements in the subauroral electrojet. For small Doppler velocities they found isotropic SNRs behaviour and at high velocities the flow angle SNR distribution is asymmetric with respect to the minima at $\theta \sim 90^{\circ}$ and $\theta \sim 270^{\circ}$. Their data have puzzling features at low $\theta$ s. Similar to André (1983), this study has a number of uncertainties due to different conditions in the backscatter volume as well as errors in the full velocity vector derivation inherent to the stereoscopic velocity merging (Uspensky et al., 2008). However, the flow angle SNR anisotropy found by Mattin and Jones (1987) does not contradict severely with the present study. Indeed, for the flow angles within $\pm 45^{\circ}$ from the orthogonality to the electron flow direction (e.g., for $\theta=45-135^{\circ}$ and $215-305^{\circ}$ ) the SNR change is less than $\sim 10 \mathrm{~dB}$. Timofeev et al. (2002) studied STARE cases (supported by the EISCAT data) with E-fields which were close to the FB instability threshold. They found (their Fig. 5) that in the eastward AEJ the maximum (minimum) power ratio for Finland (Norway) STARE radar and at the small (large) flow angles was $\sim 10(6) \mathrm{dB}$ (text in their paragraph 106 does not match Fig. 5, due to, perhaps, a misprint). The cited data are very close to what we found of this study, but they refer only to near threshold E-fields.

We note that in the above studies based on STARE and SABRE observations no data on electric field, electron density and backscatter volume height thickness were available. The electron flow direction determination and backscatter power binning according to the flow angle were performed by using the merged VHF velocities. This is a significant source of uncertainty as one can see from Nielsen and Schlegel (1985, their Fig. 2) and also from more recent results by Uspensky et al. (2008) based on larger statistics. Another important source of uncertainty is combining data collected for quite different ionosphere conditions.

Moorcroft (1996a) studied the flow angle effects in UHF backscatter ( $0.38-\mathrm{m}$ auroral irregularities) at small aspect angles for both eastward and westward AEJ. He found that (a) the backscatter power is virtually independent of the flow angle, (b) there is much less difference between type 1 and type 2 echoes, and (c) in the area of the velocity sign reversal the Doppler velocity of type 2 echoes vary with flow angle more rapidly than expected from the cosine low. Moorcroft (1996b) reported that the UHF backscatter power is essentially independent on the flow angle at large magnetic aspect angles in the AEJ. Since the UHF flow angle power dependence for a single azimuth scan was probed during limited 
time and in similar (at least roughly) ionospheric conditions, these measurements are more reliable than a multi-hour (or multi-day) statistics. Hall and Moorcroft (1992) did not find also a $48.5-\mathrm{MHz}$ backscatter power dependence upon the flow angle in Bistatic Auroral Radar System (BARS) observations.

It is well known that the flow angle variation for echo power can be weak or nearly absent for daytime auroral radar backscatter (e.g., Leadabrand, 1961). Summer daytime echoes (also in late spring and early autumn) often uniformly cover several hundred kilometres in latitude and longitude. The daytime echoes occur when the E-region is sunlit and the solar zenith angle is $<\sim 65^{\circ}$ (Unwin and Johnston, 1981) so that solar EUV is the most important contributor to the Eregion ionization.

A horizontally uniform E-region with a regular bottom part ionization gradient and the poleward E-field is an ideal place for an initial growth of large-scale GD waves. We suggest that strong presence of such waves is an important factor for the daytime (and perhaps for non-daytime) AEJ echoes. Indeed, strong low frequency waves with their electric field and electron density fluctuations could be the cause for generation of smaller-scale irregularities in a wide range of directions, even orthogonally to $V_{E \times B}$ (Farley and Balsley, 1973; Farley et al., 1994). Electric field fluctuations of a GD wave, excited in the bottom part of the E layer, can be "mapped" to higher altitudes within a height extent of $\lambda_{\|} \sim\left(\sigma_{\mathrm{O}} / \sigma_{\mathrm{P}}\right)^{1 / 2} \lambda_{\perp}$, i.e. $(50-100) \lambda_{\perp}$, where $\sigma_{\mathrm{O}}$ and $\sigma_{\mathrm{P}}$ are the parallel and Pedersen conductivities. A similar scenario can perhaps be envisioned for the bottom part of the E-layer under a non-structured diffuse particle precipitation, e.g. in the diffuse luminosity band collocating with the afternoonevening eastward AEJ. Some of our data are probably such daytime-like echoes.

The auroral E-layer in the late evening (or the midnight/morning) with the westward AEJ is much more irregular. Due to the equatorward E-field, the bottom side ionization gradient becomes damping for GD waves. In such a condition, GD waves could only be excited in local areas of suitable horizontal gradients and such the instability would be rather intermittent. In this time sector, echoes show stronger flow angle dependence for the power, e.g. Leadabrand et al. (1967), their Fig. 10; Tsunoda (1975, 1976), his Fig. 2, and Uspensky et al. (1989), their Fig. 10, where echoes in western and eastern "wings" are "connected" by much weaker echoes within a limited azimuth sector centered at the local magnetic meridian.

In the present study, the VCS flow angle variation was better noticed for the strongest echoes. These were seen at moderate flow angles of $50-70^{\circ}$. We believe that these echoes are the type 1 echoes. To test this hypothesis, we characterized the spectral width of echoes by a ratio between the double pulse (DP) ACF power (i.e. the first lag power, $R(1)$, with its real and imaginary parts measured) and the single pulse power (which was measured $20 \mathrm{~ms}$ later), $R(1)=$
$\left(\operatorname{Re}_{d p}(1)^{2}+\operatorname{Im}_{d p}(1)^{2}\right)^{1 / 2} / P_{s p}$. We found that larger VCS, on average, corresponded to a narrower spectrum which is similar to what is known for the type 1 echoes in the EEJ. Meanwhile, the moderate/weak VCSs with broader spectra would be similar to the type 2 echoes, although in our case it would be more appropriate to call them "type 2-like echoes", since in contrast to EEJ (Balsley, 1969), the AEJ Doppler velocity only slightly changes with the flow angle (Uspensky et al., 2008). Thus, the flow-angle dependent strong-power echoes and the non flow-angle dependent moderate-power echoes are similar to type 1 and type 2 echoes found in Jicamarca observations in the EEJ by Ierkic et al. (1980). Similar results on type 1/type 2 spectra were reported by Haldoupis and Nielsen (1984).

An effect that can weaken the flow angle power variation is a turbulent structure in the E-region electron flow, particularly if the spatial resolution of a radar is not sufficient to resolve a typical wavelength of such large-scale structure. In a number of auroral radar observations, e.g. by Leadabrand (1961), Leadabrand et al. (1967), Chesnut (1968), Tsunoda et al. (1974), Moorcroft and Tsunoda (1978), Moorcroft (1996a, b), the 1-o-s size of the backscatter volume was 150 (or 45) $\mathrm{km}$ with a similar volume azimuthal size (on low frequencies even larger). These radars observed both cases of weak (e.g. Moorcroft and Tsunoda, 1978, their Fig. 2) and moderate flow angle SNR power variation (e.g., Leadabrand et al., 1967, their Fig. 10).

Perhaps Jaye et al. (1969) were the first researchers who discovered that the AEJ backscatter structure can be hidden within an extended backscatter volume. These authors used $448 \mathrm{MHz}$ radar with 2.5-deg antenna beam in the Prince Albert radar laboratory (PARL) to study the auroral radar backscatter while operating with the interspersed 1-o-s resolution of $60-\mathrm{km}(400-\mu \mathrm{s} \mathrm{CW}$ pulse) and $0.9-\mathrm{km}(400-\mu \mathrm{s}$ chirp pulse compressed to $6 \mu \mathrm{s}$ ). Their aim was to relate past backscatter measurements obtained by long-pulse radars with the backscatter observed by the mentioned very short pulse radar. The data set covered both evening and morning conditions. The authors found that the VCSs were consistent with reports by others but "the volume cross sections measured with $6-\mu$ s pulses were about $10 \mathrm{~dB}$ greater than the ones determined with the long 400- $\mu$ s pulses". Their Fig. 31 (for the smallest aspect angles of $4.5-5.5^{\circ}$, for which spread of the samples was smaller) shows the mean 400- $\mu$ s VCSs of $\sim 3 \times 10^{-13} \mathrm{~m}^{-1}$ with a dispersion of $\pm 2-3 \mathrm{~dB}$ (close to the normal) that are accompanied by the mean $6-\mu$ s VCSs of $2.5 \times 10^{-12} \mathrm{~m}^{-1}$ with dispersions of $+(5-10) \mathrm{dB}$ and $-(10-$ $25) \mathrm{dB}$. The VCS distribution for the $0.9-\mathrm{km}$ resolution did not obviously follow the normal distribution. It means that patches with stronger VCS were of $\leq 0.9-\mathrm{km}$ size and they were surrounded by a plasma background filled by irregularities with much smaller backscattering coefficient. (As a supplement to the discussions above we can report that their Fig. 28a, b show less than 3-5dB SNR difference for the flow angles changing between about $\pm 45^{\circ}$ ). 
The dependence of the VCS magnitude on a 1-o-s size of the backscatter volume (if it is $\leq 1 \mathrm{~km}$ ) was confirmed independently by the $125-\mathrm{m}$ resolution observations of 3 $m$ echoes in the EEJ by Farley et al. (1994). This study illuminates the fact that the large-scale irregularities in a course of their non-linear evolution can be "seen" (as ocean waves through behaviour of the froth) by small-scale irregularities as tracers. This suggests that for strong largescale waves, the non-linear growth and decay of small-scale waves has a secondary priority. However, the small-scale waves can lose a preferential orientation with respect to the mean electron flow. Similar opinion was expressed recently by Dimant and Oppenheim (2010) in their study of plasma cloud evolution in an external electric field. They wrote: "Large-scale electric field will polarize these highly conducting clouds, redistributing the electrostatic potential and generating anisotropic currents both within and around the cloud". For a dense cloud their theory predicts highly amplified electric field around the cloud. We wonder if these effects affect additionally the non-linear evolution of the large scale plasma bursts. Random plasma wave intensity bursts are analogous to a non-regular filling of the backscatter volume by kilometre-scale waves (Jaye et al., 1969; Pfaff et al., 1987; Farley et al., 1994) and this effect can explain both the weak dependence of Doppler velocity and weak dependence of VCS magnitudes (found in this and previous studies) on the 1-o-s flow angle.

The strongest echoes are, perhaps, a product of highly turbulent plasma bursts when a large-scale dynamics with strong wave-wave coupling excites local spike-like vortices of stronger electron density and/or electric field (Pfaff et al., 1987). Similar patched backscatter dynamics was observed directly in EEJ (Farley et al., 1994, and Swartz and Farley, 1994). A high-structured backscatter was observed also in the radar interferometer observations in EEJ (Farley et al., 1981b) and in AEJ (e.g. by Providakes et al., 1985) and recently by a $30 \mathrm{MHz}$ imaging radar (Bahcevan et al., 2005, 2006, see also references therein).

One important conclusion follows from the discussion above. The largest VCSs found by Moorcroft (1987) are not the largest one due to the low spatial resolution of the auroral radars available in his analysis. The largest VCSs, inside kilometer-scale structures, are roughly $10 \mathrm{~dB}$ higher. A moderate spatial resolution of the auroral radars, we believe, does not modify the mean trend of the wave-number dependence found by Moorcroft (1987). However, the "hidden" kilometer-scale structure of irregularities can be a physical cause of a weaker flow angle dependence found for the dayevening time sector in a number studies.

\subsection{EDFA dependence upon electron drift velocity}

Significant efforts to understand SNR dependence on the electron drift velocity were undertaken by Haldoupis et al. (1990) and Shand et al. (1996). Similar to the present study, Haldoupis et al. (1990) used STARE and EISCAT measurements. They investigated the dependence of the relative receiver power on the $\boldsymbol{E} \times \boldsymbol{B}$ electron drift and ambient electron density for both evening and morning sector data. Importance of the volume cross section as a physical parameter of the media the authors expressed in their Sect. 2. Their Eqs. (2) and (4) suggest the isotropic scattering from the volume unit, although the explanation on p. 196 (1st section, the right column), implies the scattering per unit solid angle. These two approaches have the VCS difference by a factor $4 \pi$. The authors did not utilize the EISCAT $N(h)$ profiles to correct the echo power on the backscatter layer thickness and/or the aspect angle. Shand et al. (1996) considered simply the backscatter power.

In the present study we supplemented our estimates of the volume cross section by EISCAT data on the electron drift velocity, effective electron density, backscatter volume height thickness and $N(h)$-profile dependent variations of the aspect angle. After correction on the volume height thickness (largest was $\sim 4 \mathrm{~dB}$ ) and the aspect angle (largest was $\sim 6 \mathrm{~dB})$ we assigned all absolute VCS values to the effective aspect angle of $\sim 0.9^{\circ}$. Our largest measured VCSs were $10^{-8}-10^{-9} \mathrm{~m}^{-1}$; for such VCS the echoes had smaller spectral width and enhanced Doppler velocity. They were seen at moderate flow angles of $50-70^{\circ}$ and looked like primaries or flow-angle affected type 1 echoes. The strongest echoes occurred mainly when electron drift velocities were over $\sim 1000 \mathrm{~m} \mathrm{~s}^{-1}$ and the effective electron densities were between $\sim 0.6 \times 10^{11} \mathrm{~m}^{-3}$ and $\sim 1.5 \times 10^{11} \mathrm{~m}^{-3}$.

Moderate VCSs, which probably were mixed type 1 and type 2 echoes, looked like a scatter from the secondaries. These echoes were almost insensitive to the flow angle variations; their VCSs were proportional to the product of the squared electron drift velocity and the squared volume ionisation $\sigma_{\mathrm{v}} \propto\left(N_{\mathrm{e}}^{\text {eff }} V_{E \times B}\right)^{2}$, Fig. 5a, b. Appearance of echoes with 5-50 times larger VCSs, which we relate to type 1 echoes is an indication that another mechanism can be responsible for excitation of these flow-angle dependent irregularities. Indeed, they did not follow the $\left(N_{\mathrm{e}}^{\mathrm{eff}} V_{E \times B}\right)^{2}$-trend fitted for the moderate VCSs, appearing on 3-5 times smaller $\left(N_{\mathrm{e}}^{\mathrm{eff}} V_{E \times B}\right)^{2}$-values (data are not shown). Partly they are the largest VCSs in Fig. 5a, b.

We noticed that the weakest echoes with $\sigma_{\mathrm{v}} \tilde{<} 3 \times$ $10^{-11} \mathrm{~m}^{-1}$ occurred for large electron drift velocity $(700$ $\left.1400 \mathrm{~m} \mathrm{~s}^{-1}\right)$ but small effective electron density $(0.2-$ $\left.0.3 \times 10^{11} \mathrm{~m}^{-3}\right)$. We wonder if in such cases the larger EDFAs could appear under smaller ionisation, similar as in Fig. 6a, b.

Published so far rocket measurements of EDFA give good idea about typical numbers. Kelley and Mozer (1973) found that the broadband EDFAs $(50-1000 \mathrm{~Hz})$ between $\sim 90$ and $\sim 120 \mathrm{~km}$ were $7-10 \%$. Their measurements were performed during strong auroral substorm at its expansion phase with ground magnetic variations in excess of $2000 \mathrm{nT}$ and the background electric field between 50 and $85 \mathrm{mV} \mathrm{m}^{-1}$. EDFA 
values of $4-5 \%$, also in the frequency band of $50-1000 \mathrm{~Hz}$, were measured by Pfaff et al. (1984) during moderate/weak positive magnetic bay of $87 \mathrm{nT}$ with the electric field of $54 \mathrm{mV} \mathrm{m}^{-1}$. EDFA magnitudes of 3-10\% were measured in the Antarctic auroral E-region by Ogawa et al. (1976). The frequency band of their measurements was from a few hertz to $160 \mathrm{~Hz}$. In the ROSE rocket flight from Andenes, Norway, Schlegel (1992) found the evening EDFAs of 2.5-3.5\% in condition with the electric field of $\sim 37 \mathrm{mV} \mathrm{m}^{-1}$ and the instrument frequency band of $10-1000 \mathrm{~Hz}$.

Despite of a spread in individual points, our radarestimated EDFAs of 2-5\% (Sect. 5) are reasonably consistent with in situ rocket measurements, and both the Norway and Finland STARE radar data are mutually supported. The curves in Fig. 6a, b show that the electron density fluctuations are significant for the electron drift velocity above $400-500 \mathrm{~m} \mathrm{~s}^{-1}$. For larger velocities, roughly up to $1000 \mathrm{~m} \mathrm{~s}^{-1}$, the fluctuation amplitude increases almost linearly. For the electron drift velocity larger than $\sim 1000 \mathrm{~m} \mathrm{~s}^{-1}$, the rate of the EDFA increase experiences the saturation effect. Similar conclusions based on solely STARE data were obtained earlier by Uspensky et al. (1983a, b) as well as on the STARE-EISCAT data (but for much smaller statistics) and the method by Oksman et al. (1986) were obtained by Nielsen et al. (1988). The features mentioned are consistent with the expected behaviour of the FB instability which includes: (a) threshold for excitation of the instability at the electron drift velocity close to the ion-acoustic speed, $\sim 400 \mathrm{~m} \mathrm{~s}^{-1}$, (b) a linear increase of the fluctuations with increase of electron drift velocity, (c) the turbulence level saturation when nonlinear wave losses becomes progressively enhanced (Fejer and Kelley, 1980; Farley, 2009).

Moorcroft (1987) carefully discussed the EDFA estimates by Oksman et al. (1986), based on his data on the largest VCSs at different radar frequencies. He found the estimates to be reasonable ones for the radar frequencies below $200 \mathrm{MHz}$. At higher frequencies, the Oksman et al.'s (1986) method, applied to largest VCSs, overestimates EDFAs due to the exponential form of the frequency dependence. In this study, we did not change the frequency dependence since it is based on the experimental data by Chesnut et al. (1968) for, perhaps, moderate VCSs. The Moorcroft (1987) dependence is based on largest VCSs. It is interesting that the spatial power spectrum is different in different geophysical conditions and we are leaving this point open for future studies.

The best check of our findings regarding EDFA would be a direct rocket measurement. Unfortunately, such data are not available to the authors. EDFA estimates based on STARE measurements were also performed by Walker et al. (1987). Their estimates of the RMS density fluctuations as a function of STARE signal-to-noise ratio (their Fig. 2b) are too high. For SNR $\sim 15 \mathrm{~dB}$ the authors found that $\log \left(<\delta N^{2}>\right)^{1 / 2} \sim 4.5$ per cubic centimetre. If one selects the E-region electron density of $\sim 10^{11} \mathrm{~m}^{-3}$ (this is a slightly increased value) or a mean of $0.7 \times 10^{11} \mathrm{~m}^{-3}$ (as it is in the middle panels of our Figs. 2 and 3), then their RMS density fluctuations would be $30-40 \%$, which seems to be a significant overestimate.

\section{Summary}

The new findings of this study can be summarized as follows.

We showed the weak flow angle dependence of the STARE VCSs in the eastward AEJ for the flow angles of $40-85^{\circ}$ and electron drifts of up to $2000 \mathrm{~m} \mathrm{~s}^{-1}$. This is in contrast to stronger power variation reported by André (1983) and Mattin and Jones (1987). The difference, perhaps, originated from the fact that previous STARE statistics included measurements in the morning sector. In addition, no data for flow angles of $<40^{\circ}$ were included in the present analysis.

We improved the radar method of the electron density fluctuation amplitude estimation from STARE data by obtaining analytical expression for the spatial power spectrum of auroral irregularities that involves weaker flow angle variation and more precise $k$ dependence.

Inferred values of the electron density fluctuation amplitude (from absolute values of the STARE radar VCSs and the EISCAT-measured ionospheric parameters) of $2-5 \%$ were found reasonably consistent with published in situ rocket measurements.

The electron density fluctuation amplitude shows a linear increase with the electron drift velocity up $\sim 1000 \mathrm{~m} \mathrm{~s}^{-1}$ and starts to saturate at larger drifts.

Acknowledgements. The STARE system was operated jointly by Max Plank Institute for Aeronomy, Germany, and Finnish Meteorological Institute, Finland, in cooperation with SINTEF, University of Trondheim, Norway. EISCAT is an international facility supported by Finland, France, Germany, Japan, Norway, Sweden and the UK. This work was supported by the research project 115947 of the Academy of Finland. AVK acknowledges NSERC (Canada) funding. MVU wants sincerely thank W. G. Chesnut and D. R. Moorcroft who has allowed him to be acquainted with the early PARL auroral backscatter measurements (Jaye et al., 1969) used in this study. MVU wants also to express his gratitude to AriMatti Harri, FMI, for providing an efficient and fruitful working environment. The authors thank A. Kozlovsky and Yu. Zarnitsky for help and useful discussions.

Editor-in-Chief M. Pinnock thanks two anonymous referees for their help in evaluating this paper.

\section{References}

André, D.: The dependence of the relative backscatter cross section of 1-m density fluctuations in the auroral electrojet on the angle between electron drift and radar wave vector, J. Geophys. Res., 88(10), 8043-8049, 1983.

Bahcevan, H., Hyssel, D. L., Larsen, M. F., and Pfaff, R. F.: The $30 \mathrm{MHz}$ imaging radar observations of auroral irregularities during the JOULE campaign, J. Geophys. Res., 110, A05307, doi:10.1029/2004JA010975, 2005. 
Bahcevan, H., Hyssel, D. L., Lummerzheim, D., Larsen, M. F., and Pfaff, R. F.: Observations of collocated optical and radar aurora, J. Geophys. Res., 111, A12308, doi:10.1029/2006JA011923, 2006.

Balsley, B. B.: Some characteristics of non-two-stream irregularities in the equatorial electrojet, J. Geophys. Res., 74(9), 23332347, 1969.

Buchert, S. C., Hagfors, T., and McKenzie, J. F.: Effect of electrojet irregularities on DC current flow, J. Geophys. Res., 111, A02305, doi:10.1029/2004JA010788, 2006.

Chesnut W.: Low frequency waves and irregularities in the auroral ionosphere as determined by radar measurements. Low frequency waves and irregularities in the ionosphere, edited by: D’Angelo, N., Dordrecht D. Reidel, 173-191, 1968.

Dimant, Y. S. and Oppenheim, M. M.: Interaction of plasma cloud with external electric field in lower ionosphere, Ann. Geophys., 28, 719-736, doi:10.5194/angeo-28-719-2010, 2010.

Farley, D. T.: Theory of equatorial electrojet plasma waves: new developments and current status, J. Atmos. Terr. Phys., 47(8/10), 729-744, 1985.

Farley, D. T.: The equatorial E-region and its plasma instabilities: a tutorial, Ann. Geophys., 27, 1509-1520, doi:10.5194/angeo-271509-2009, 2009

Farley, D. T. and Balsley, B. B.: Instabilities in the equatorial electrojet, J. Geophys. Res., 78(1), 227-239, 1973.

Farley, D. T., Ierkic, H. M., and Fejer, B. G.: The absolute scattering cross section at $50-\mathrm{MHz}$ of equatorial electrojet irregularities, J. Geophys. Res., 86(3), 1569-1575, 1981a.

Farley, D. T., Ierkic, H. M., and Fejer, B. G.: Radar interferometry: A new technique for studing plasma turbulence in the ionosphere, J. Geophys. Res., 86(3), 1467-1472, 1981b.

Farley, D. T., Swartz, W. E., Hysell, D. L., and Ronchi, C.: Highresolution radar observations of daytime kilometre-scale wave structure in the equatorial electrojet, J. Geophys. Res., 99(A1), 299-307, 1994.

Fejer, B. G. and Kelley, M. C.: Ionospheric irregularities, Rev. Geophys. Space Phys., 18(2), 401-454, 1980.

Greenwald, R. A., Weiss, W., Nielsen, E., and Thomson, N. R.: STARE: A new radar auroral backscatter experimennt in Northern Scandinavia, Radio Sci., 13(6), 1021-1029, 1978.

Haldoupis, C. and Nielsen, E.: Results on relative scattering cross section of 140-MHz auroral backscatter, J. Geophys. Res., 89(4), 2305-2312, 1984.

Haldoupis, C., Nielsen, E., and Schlegel, K.: Dependence of radar auroral scattering cross section on the ambient electron density and the destabilizing electric field, Ann. Geophys., 8, 195-212, 1990

Hall, G. E. and Moorcroft, D. R.: Magnetic aspect angle effects in radar aurora at $48,5 \mathrm{MHz}$, corrected for refraction, J. Geophys. Res., 97(A12), 19471-19488, 1992.

Ierkic, H. M., Fejer, B. G., and Farley, D. T.: The dependence on zenith angle of the strength of 3-m equatorial electrojet irregularities, Geophys. Res. Lett., 7(7), 497-500, 1980.

Jaye, W. E., Chesnut, W. G., and Craig, B.: Analysis of auroral data from Prince Albert radar laboratory, Stanford Res. Inst., 90, 1969

Kelley, M. C., and Mozer, F. S.: Electric field and plasma density oscillations due to the high-frequency Hall current two-stream instability in the auroral E region, J. Geophys. Res., 78(13),
2214-2221, 1973.

Koustov, A. V., Danskin, D. W., Uspensky, M. V., Ogawa, T., Janhunen, P., Nishitani, N., Nozawa, S., Lester, M., and Milan, S.: Velocities of auroral coherent echoes at 12 and $144 \mathrm{MHz}$, Ann. Geophys., 20, 1647-1661, doi:10.5194/angeo-20-16472002, 2002.

Leadabrand, R. L.: A note on the disposition of daytime ionization in space, J. Geophys. Res., 66, 421-428, 1961.

Leadabrand, R. L., Larson, A. G., and Hodges, J. C.: Preliminary results on the wavelength dependence and aspect sensitivity of radar auroral echoes between 50 and $3000 \mathrm{MHz}$, J. Geophys. Res., 72(15), 3877-3887, 1967.

Mattin, N. and Jones, T. B.: Propagation angle dependence of radar auroral E-region irregularities, J. Atmos. Terr. Phys., 49(2), 115121, 1987.

Moorcroft, D. R.: Estimates of absolute scattering coefficients of radar aurora, J. Geophys. Res., 92(8), 8723-8732, 1987.

Moorcoft, D. R.: Flow angle effects in E region 398-MHz auroral backscatter at small aspect angles, J. Geophys. Res., 101, 1337913386, 1996a.

Moorcroft, D. R.: A statistical study of UHF auroral backscatter at large magnetic aspect angle: A reanalysis of unpublished results from 1968, J. Geophys. Res., 101, 11005-11011, 1996 b.

Moorcroft, D. R. and Tsunoda, R. T.: Rapid scan Doppler velocity maps of the UHF diffuse radar aurora, J. Geophys. Res., 83(4), 1482-1492, 1978.

Nielsen, E.: The STARE system and some of its applications, in: IMS Source Book Guide to the International Magnetospheric Study Data Analysis. Washington, D.C., AGU, edited by: Russel, C. T. and Southwood, D. J., 213-224, 1982.

Nielsen, E. and Schlegel, K.: Coherent radar Doppler measurements and their relationship to the ionospheric electron drift velocity, J. Geophys. Res., 90(4), 3498-3504, 1985.

Nielsen, E., Uspensky, M., Kustov, A., Huuskonen, A., and Kangas, J.: On the dependence of the Farley-Buneman turbulence level on ionospheric electric field, J. Atmos. Terr. Phys., 50(7), 601-605, 1988.

Ogawa, T., Mori, H., and Miyasaki, S.: Rocket observations of electron density irregularities in the Antarctic auroral E region, J. Geophys. Res., 81(22), 4013-4015, 1976.

Ogawa, T., Mori, H., Miyazaki, S., and Yamagishi, H.: Electrostatic plasma instabilities in highly active aurora observed by sounding rocket S-310JA-7, Mem. Natl. Inst. Polar Res. Spec. Issue, 18, 312-329, 1981.

Oksman, J., Uspensky, M. V., Starkov, G. V., Stepanov, G. S., and Vallinkoski, M.: The mean fractional electron density fluctuation amplitude derived from auroral backscatter data, J. Atmos. Terr. Phys., 48(2), 107-113, 1986.

Pfaff, R. F., Kelley, M. C., Fejer, B. G., Kudeki, E., Carlson, C. W. Pedersen, A., and Hausler, B.: Electric field and plasma density measurements in the auroral electrojet,J. Geophys. Res., 89(1), 236-244, 1984.

Pfaff, R. F., Kelley, M. C., Kudeki, E., Fejer, B. G., and Baker, K. B.: Electric field and plasma density measurements in the strongly driven daytime equatorial electrojet. II. Two-stream waves, J. Geophys. Res., 92(12), 13597-13612, 1987.

Providakes, J., Farley, D. T., Swartz, W. E., and Riggin, D.: Plasma irregularities associated with a morning discrete auroral arc: radar interferometer observations and theory, J. Geophys. Res., 
90(8), 7513-7523, 1985.

Schlegel, K.: Measurements of electron density fluctuations during the ROSE rocket flights, J. Atmos. Terr. Phys., 54, 715-723, 1992.

Schlegel, K.: Coherent backscatter from ionospheric E-region plasma irregularities, J. Atmos. Terr. Phys., 58, 933-941, 1996.

Schlegel, K. and St.-Maurice, J.-P.: Anomalous heating of the polar E region by unstable plasma waves. 1. Observations. J. Geophys. Res., 86, 1447-1452, 1981.

Shand, B. A., Lester, M., and Yeoman, T. K.: The relationship between VHF radar auroral backscatter amplitude and Doppler velocity: a statistical study, Ann. Geophys., 14, 803-810, doi:10.1007/s00585-996-0803-2, 1996.

Starkov, G. V., Oksman, J., Uspensky, M. V., and Kustov, A. V.: On the dependence of radar aurora amplitude on ionospheric electron density, J. Geophys., 52, 49-52, 1983.

Swartz, W. E. and Farley, D. T.: High-resolution radar measurements of turbulent structure in the equatorial electrojet, J. Geophys. Res., 99(A1), 309-317, 1994.

Timofeev, E. E., Vallinkoski, M. K., Pollari, P., Kangaas, J., Virdi, T., Williams, P. J. S., and Nielsen, E.: Flow angle dependence of 1-m ionospheric plasma wave turbulence for near-threshold radar echo electric fields, J. Geophys. Res., 107(A10), 1286, doi:10.1029/2000JA005023, 2002.

Tsunoda, R. T.: Electric field measurements above a radar scattering volume producing diffuse auroral echoes, J. Geophys. Res., 80(31), 4297-4306, 1975.

Tsunoda, R. T.: Doppler velocity maps of the diffuse radar aurora, J. Geophys. Res., 81(4), 425-435, 1976.
Tsunoda, R. T., Presnell, R. I., and Leadabrand, R. L.: Radar aurora echo characteristics as seen by a 398-MHz phased array radar operated at Homer, Alaska, J. Geophys. Res., 79(31), 4709-4724, 1974.

Unwin, R. S. and Johnston, P. V.: Height dependence in the power spectrum diffuse radar aurora, J. Geophys. Res., 86(7), 57335745, 1981.

Uspensky, M. V., Baumjohann, W., Pellinen, R. J., and Starkov, G. V.: Experimental data on electric field and electron density dependence of auroral E-region drift turbulence and radar backscatter, J. Geophys., 53, 198-200, 1983a.

Uspensky, M. V., Pellinen, R. J., Baumjohann, W., Starkov, G. V., Nielsen, E., Sofko, G., and Kaila, K. U.: Spatial variations of ionospheric conductivity and radar auroral amplitude in the eastward electrojet region during pre-substorm conditions, J. Geophys., 52, 40-48, 1983 b.

Uspensky, M. V., Starkov, G. V., Stepanov, G. S., and Williams, P. J. S.: The amplitude of auroral backscatter: 2. Topology of the backscatter range-azimuth distribution, J. Atmos. Terr. Phys., 51(11/12), 926-936, 1989.

Uspensky, M., Koustov, A., Janhunen, P., Nielsen, E., Kauristie, K., Amm, O., Pellinen, R., Opgenoorth, H., and Pirjola, R.: STARE velocities: 2. Evening westward electron flow, Ann. Geophys., 22, 1077-1091, doi:10.5194/angeo-22-1077-2004, 2004.

Uspensky, M. V., Pellinen, R. J., and Janhunen, P.: The electron drift velocity, ion acoustic speed and irregularity drifts in high-latitude E-region, Ann. Geophys., 26, 3395-3409, doi:10.5194/angeo26-3395-2008, 2008.

Walker, A. D. M., Greenwald, R. A, and Baker, K. B.: Determination of the fluctuation level of ionospheric irregularities from radar backscatter measurements, Radio Sci., 22, 689-705, 1987. 